\title{
Willingness to Communicate in English among non- English Major Malaysian Undergraduates
}

\author{
Siti Bahirah Saidi \\ bahirah@umk.edu.my \\ Centre for Language Studies and Generic Development, Universiti Malaysia Kelantan
}

\begin{abstract}
Current policies to second language teaching (L2) put great emphasis on improving the communicative skills of the learners. Teachers, however, found that some learners avoid L2 communication despite their excellent proficiency level in the target language. The literature on learners' reticence highlights the considerable number of studies available on willingness to communicate (WTC). However, most of the studies were conducted in the contexts that bear little resemblance to a multicultural Malaysia. The present study aimed to explore how interlocutors and contexts contribute to the participants' WTC level. Data were gathered through face-to-face interviews $(n=14)$. The findings revealed that the participants' WTC fluctuate across interlocutors and contexts. The evidence from the current findings confirms the notion that WTC is a dynamic variable. However, the present data offers an alternative view concerning fluctuation across interlocutors. The paper concludes with pedagogical implications.
\end{abstract}

Keywords: willingness to communicate; non-English major; second language; Malaysia; ethnicity.

\section{Introduction}

Due to the crucial role of communication in learning a language, the construct Willingness to communicate in English (L2WTC) has received growing attention from the researchers worldwide. Kang [1] proposes that L2 WTC is "an individual's volitional inclination towards actively engaging in the act of communication in a particular situation, which can vary according to the interlocutor(s), topic, and conversational context, among other potential situational variables" (p. 291). Researchers argue that L2 learners' WTC is influenced by their cultural backgrounds, by how they perceive themselves in comparison to the native speakers' performances, and by their own volition [2-4]. WTC research in Western contexts, conducted within plural societies, has focused on the effect of multiculturalism on WTC. Meanwhile, WTC research in non-Western contexts has shown how cultures, (especially Asian cultures) have attributed to low WTC among L2 learners. Collectively, WTC research in both Western and non-Western contexts highlights the key role culture and identity play in determining learners' willingness to communicate. What is not yet clear is the impact of interlocutors and context on Malaysian non-Western multicultural learners' WTC. This study seeks to address the following questions:

1. How willing are Malaysian undergraduates to communicate in English on campus?

2. How do interlocutors and context influence Malaysian undergraduates' willingness to communicate in English? 


\section{Kresna Social Science and Humanities Research}

Proceedings of the International Conference On Ummah:

Digital Innovation, Humanities And Economy (ICU: DIHEc) 2020

https://doi.10.30874/ksshr.30

\section{English in Malaysia}

Linguistically, the Malay language, or Bahasa Malaysia (referred to as BM henceforth), is the national and first official language of the country, while English is the second official language. It is important to note here that although most Malaysians are bilingual, different mother tongue (home language) typically equates with an ethnicity. For instance, Mandarin relates Chinese and Tamil equates Indian. However, there is an exception to this situation, particularly in urban settings, where English is the home language (L1) to some families. Regarding educational policy, in 'National' schools, BM is the medium of elementary education. At the secondary level, the Malay medium is the only publicly supported schooling available. While BM is the medium of instruction at the school level, it is different at the tertiary education level. All public institutions of higher education, except for MARA University of Technology (UiTM) and International Islamic University Malaysia (IIUM), use BM as the medium of instruction. In comparison, most private higher education institutions use the English language. Despite 11 years spent learning English at school, many Malaysian learners appear to have a negative attitude towards communicating in English [5,6]. The perplexing situation of meeting stakeholders' expectation to produce graduates with good English language proficiency, therefore, is a cause for concern among English language educators in Malaysia. The present study, therefore, seeks to address the English fluency issue by examining its root by examining learners' L2 WTC. Findings from the analysis of how interlocutors and contexts influence learners' L2 WTC should lead to lessons for Malaysia and other countries seeking to improve their undergraduates' English fluency and eventually upgrade their human capital.

\section{Methodology}

\subsection{Research site}

The research setting was a university in Kelantan, one of the most conservative states in Malaysia, where the use of English is confined mainly to the language classrooms. The students come from all 14 states of Malaysia, with diversity in socio-economic background, as well as ethnicity and proficiency levels. In other words, the students who enrolled in the university reflect the enrolment in the majority of public universities in Malaysia.

\subsection{Participants}

Participants were non-English major undergraduates who were studying at a university in Kelantan. There were four Malay, four Indian, and six Chinese interviewees.

\subsection{Data collection}

On average, the face-to-face interview lasted around 40 minutes, except with two participants, one of which lasted only seventeen minutes and the other one hour. The interviews were recorded and transcribed, and then the transcripts were coded. All participants used English throughout the interview, except when they struggled for the best expression to illustrate their 


\title{
Kresna Social Science and Humanities Research
}

Proceedings of the International Conference On Ummah:

Digital Innovation, Humanities And Economy (ICU: DIHEc) 2020

https://doi.10.30874/ksshr.30

points, where they resorted to BM. Extracts were translated to be included in the final manuscript.

\subsection{Data analysis}

The qualitative data that came from the face-to-face interview was transcribed before being thematically analysed by using ATLAS.ti 8 package.

\section{Findings}

The participants admitted that they were reluctant to communicate in English on campus. The reticence happened because there were limited places that they could converse in English, for example, in some English classes where English was made compulsory, and at a debate club. It was perceived that communicating in English outside these boundaries was improper, as the participants were consistently worried about the effect of using English in this setting. Meng (Chinese) viewed using English in the university as something unnatural, a guilt-ridden act. The perception that one should not freely communicate in English in the university setting was probably rooted in the widespread practice of the university members, where almost everyone was either conversing in the mother tongue or the local Kelantanese dialect. Chong voiced criticism of this situation:

The lecturers are unwilling to use English. The staff are worse; they use [the] Kelantanese dialect. Almost no one is willing to use English here, except for the Indian students. (Chong, Chinese)

These participants' low WTC levels increased when they returned to their hometown, where English was widely spoken. Unfortunately, the limited use of English during the university days led to lower English fluency:

\begin{abstract}
When I return to my hometown in Malacca, I'll struggle to construct my sentences. In Kelantan, I have to use simple English sentences to communicate. When I return to Malacca, my friends found my sentences a bit weird. Then I explain to them that this is the English I use in Kelantan to make people understand. Then my friends just laughed at me. I told them, please don't laugh. Go to Kelantan; then you'll know how hard it is. (Rita, Indian).
\end{abstract}

The above accounts by the participants suggest setting or context play a very significant role in the participants' WTC levels.

\subsection{Theme 1: WTC with Peer Students}

WTC with peer students is divided into two sub-themes: WTC with a peer of the same L1 and WTC with a peer of a different L1. All 14 participants were reluctant to communicate in English with a peer student of the same L1, except if they knew the peer students received English- 


\section{Kresna Social Science and Humanities Research}

Proceedings of the International Conference On Ummah:

Digital Innovation, Humanities And Economy (ICU: DIHEc) 2020

https://doi.10.30874/ksshr.30

medium education during their school years: "In this university, 95\% won't use English. I would say most of the Indian students prefer to speak Tamil. Only those from Convent schools use English." (Rita, Indian). This unwillingness heightened if they perceive their peer students' proficiency levels were lower than theirs.

[I am] not willing. I don't want them [my Indian friends] to think I'm trying to show off. Most of them are not proficient in English. (Anjali, Indian).

However, this reluctance turned into willingness at a venue where the use of English is expected and required. For instance, if they were having a lesson and the instructor insisted everyone use English: "If the lecturer speaks English throughout the whole class, I'll definitely use English" (Kenny, Chinese). On the other hand, all 14 participants expressed their willingness to communicate in English with a peer student of a different L1: "I'm comfortable to speak English when I'm with Indian or Chinese friends'. (Ani, Malay). Most of the participants were willing to communicate in English with high proficiency interlocutors:

[I'm more willing to communicate in English] with the more proficient ones. Because they understand what I'm trying to say. (Arif, Malay)

However, two of the participants were unwilling to communicate with peer learners of higher proficiency. The first participant perceived communicating with high proficiency interlocutors as a threat to her self- confidence:

[I'm reluctant to speak English] to the ones who are good in English... They might think I'm not brilliant...I don't have the confidence. (Ani, Malay)

Meanwhile, another student mentioned his reluctance was due to his inability to construct sentences within appropriate time:

Not willing. When I use English with those with higher proficiency, I made them wait, as I struggle to come up with sentences. (Chong, Chinese)

In short, the participants were willing to communicate in English with peer learners of different L1 but became more selective when it concerned peers of the same L1.

\subsection{Theme 2: WTC with Instructors}

The participants expressed their WTC in English with the lecturers whom they knew expected them to do so. This reply is typical: "Yes [I'm willing to communicate with English lecturers]. We are expected to use English with them" (Rani, Indian). Unsurprisingly, most of the participants were similar in their willingness to communicate in English with lecturers teaching English. Unlike WTC with peers, the participants' WTC with lecturers was not based on the lecturers' ethnicity but on the lecturers' English proficiency levels. All participants expressed 


\section{Kresna Social Science and Humanities Research}

Proceedings of the International Conference On Ummah:

Digital Innovation, Humanities And Economy (ICU: DIHEc) 2020

https://doi.10.30874/ksshr.30

WTC with lecturers they perceived as having good proficiency levels, and unwillingness to communicate with lecturers whom they felt were not as proficient in English. The participants evaluated the lecturers' proficiency based on the language they used when teaching in class.

Yes [I'm willing to communicate in English with my lecturers], especially with those lecturers who use English in class. There are lecturers whom I can't use English with, those who teach their subjects solely in Malay. If I speak to them in English, I wonder whether they understand what I'm saying. (Kajol, Indian)

Consequently, participants' WTC in English with their instructors was limited to the few English-speaking instructors.

The interview findings reveal that the participants' WTC fluctuates based on the context they are in. The participants mentioned having higher WTC before coming to the university (when they were in their hometown) and decreased WTC when they were in the university setting. This low WTC will increase when they return to their hometown during university semester breaks. Surprisingly, the effect of the interlocutor/audiences on the participants' WTC was confined to only the university setting.

\section{Discussion and Conclusion}

This study explored how interlocutors and contexts influenced Malaysian learners' WTC. The findings show that the participants have low WTC level. However, the low WTC level is not constant; instead, it fluctuates based on the venues and interlocutors. The participants reported higher WTC when they are in their hometown, but lower WTC when they are on the university grounds. On-campus, this low WTC increases when they are in a venue where they perceive the use of English is not only permissible but expected. As for WTC across interlocutors, the fluctuations are based on the interlocutors' proficiency and ethnicity. WTC is low with lecturers and peers who are perceived as having poor English proficiency, as well as with peers of the same ethnicity.

The evidence from the current findings lends support and provides elaboration upon existing findings in WTC literature. It confirms the notion that WTC is a dynamic variable that fluctuates across contexts and interlocutors. However, the present data offers an alternative view concerning fluctuation across interlocutors. To the researcher's knowledge, this is the first evidence that shows learners have (un)WTC with interlocutors who have lower English proficiency levels in order to protect the interlocutors' face. This evidence is also perhaps among the first studies to document (un)WTC in English with interlocutors of the same ethnicity.

This finding has offered a new and exciting observation concerning the influence of collective culture on learners' WTC: the participants were reluctant to communicate in English with interlocutors of lower proficiency levels in order not to threaten their face and dignity. To the researcher's knowledge, this observation is the first of its kind to be documented in the WTC literature. The current study makes a significant contribution to the existing body of literature in understanding WTC in English among undergraduates, not only in the context of Malaysia but also at the regional and international levels. While it has built on reports in the literature of previous studies on learners' WTC, this study distinguishes itself from earlier studies through 


\section{Kresna Social Science and Humanities Research}

Proceedings of the International Conference On Ummah:

Digital Innovation, Humanities And Economy (ICU: DIHEc) 2020

https://doi.10.30874/ksshr.30

its focus on those challenges related to learners' WTC, which apply mainly to Malaysia and other non-Western plural societies more generally.

The present study has widened and expanded the scope of WTC research. To date, most WTC studies were confined to the language classroom [7]. By taking into consideration the meaning of communicative setting (which specifies that a communicative environment is not restricted to language classrooms but instead matches the outside classroom settings), this research has problematised WTC on campus as WTC both in and outside of language classrooms.

Acknowledgements. This study was part of a PhD project conducted at the University of York, UK. Many thanks to Universiti Malaysia Kelantan for financial support.

\section{References}

[1] Kang, S. J. Dynamic emergence of situational willingness to communicate in a second language. System. 2005; 33(2): 277-292.

[2] Clément, R., Baker, S. C., \& MacIntyre, P. D. Willingness to communicate in a second language: The effects of context, norms, and vitality. Journal of Language and Social Psychology. 2003; 22(2): 190-209.

[3] Croucher, S. M.. Communication apprehension, self-perceived communication competence, and willingness to communicate: A French analysis. Journal of International and Intercultural Communication. 2013; 6(4): 298-316.

[4] Wood, D. Willingness to communicate and second language speech fluency: An idiodynamic investigation. System. 2016; 60: 11-28.

[5] Rajadurai, J.. "Malays are expected to speak Malay": Community ideologies, language use and the negotiation of identities. Journal of Language, Identity \& Education. 2010; 9(2), $91-106$.

[6] Wahi, W.. English language literacies of undergraduate students in Malaysia's culturally and linguistically diverse environment: Casualties of National Language Policies and globalisation? Education Research and Perspectives. 2015; 42, 329-362.

[7] Joe, H.-K., Hiver, P., \& Al-Hoorie, A. H.. Classroom social climate, self-determined motivation, willingness to communicate, and achievement: A study of structural relationships in instructed second language settings. Learning and Individual Differences. 2017; 53, 133-144. 